\title{
Teach students, Empower patients, Act collaboratively and Meet health goals: an early interprofessional clinical experience in transformed care
}

This article was published in the following Dove Press journal:

Advances in Medical Education and Practice

\author{
Maria Gabriela Castro' \\ Melanie Dicks ${ }^{2}$ \\ Keisa Fallin-Bennett ${ }^{\prime}$ \\ Carol Hustedde' \\ David Sacks' \\ Lynn Joyce Hunter ${ }^{3}$ \\ William Elder' \\ 'Department of Family and \\ Community Medicine, University \\ of Kentucky, Lexington, KY, USA; \\ ${ }^{2}$ College of Pharmacy, University \\ of Kentucky, Lexington, KY, USA; \\ ${ }^{3}$ College of Social Work, University of \\ Kentucky, Lexington, KY, USA
}

Correspondence: William Elder

UK-Healthcare at Turfland, 2195

Harrodsburg Road, Suite 125, Lexington,

KY 405I7, USA

Tel + I $859323637 \mid$

Fax +| $859257723 \mid$

Email welder@uky.edu
Purpose: Transformation of care teaching is often didactic and conceptual instead of practical and operational. Clinical environments, slow to transform, limit student exposure to key experiences that characterize transformed care. We describe the design and implementation of TEAM Clinic (Teach students, Empower patients, Act collaboratively, Meet health goals) - an early clinical learning experience to address this gap.

Methods: The TEAM Clinic curriculum was based on a review of existing curricula and best practice recommendations for the transformation of care. Three key elements were selected as the focus for a low-volume, high-service clinic: patient centeredness, interprofessional collaboration and team-based care. Learners and medically and socially complex patients were recruited for voluntary participation and completed anonymous surveys about the experience during and afterward.

Results: Nine first-year medical students, two first-year social work students and one pharmacy resident were integrated into the interprofessional team. Students were assigned roles adapted to their level and skill set; deliberate interprofessional pairing was assigned to broaden perspectives on scope and role of team members. Upon completion of this two-semester experience, 11 of the 12 learners returned surveys; all rated the experience as positive (strongly agree or agree) on the Authentic Clinical Interprofessional Experience - Evaluation of Interprofessional Site tool. Patient surveys indicated satisfaction with multiple aspects of the visit.

Conclusion: TEAM Clinic provided a practical example of transformation of care teaching in a not-yet-transformed environment. Logistical barriers included space, schedule and staffing. Facilitators included alignment with the goals of core curricula and faculty. Limitations included that this description of these curricula and this pilot come early in our longitudinal development of TEAM Clinic, constraining our ability to measure behavioral changes around interprofessional education, teamwork or patient centeredness. Next steps would examine the trajectory to these outcomes in the preclinical student group.

Keywords: medical education, practice transformation, interprofessional education

\section{Introduction}

Medical educational reform is necessary to prepare future physicians to understand and lead in high-functioning and complex health care systems. ${ }^{1,2}$ The transition to health care based on quality involves multiple elements, key among them being true interprofessional collaboration. We refer to this evolution as transformation of care and the result as transformed systems or environments; however, a huge 
challenge to training health professionals to provide such teamwork is the lack of access to current working models. Educational redesign must reflect a new role and skill set required for physicians to catalyze changes needed for the present and future health care environment. Expanded competencies to succeed in transformed environments have been identified and include working within the system, shared decision making, working across disciplines and working to improve the system. ${ }^{3}$ To this end, medical school curricula now need to reflect a focus on the development of professional identity and habits of the mind as students prepare for collaborative work in interprofessional environments. Although these advances in pedagogy present ripe opportunities for educational reform, the slow transformation of current practice to reflect key components of transformed care environments presents a significant practical limitation for clinical educators.

The Institute of Medicine's 2003 recommendation for health professionals to provide patient-centered, teambased care highlights the importance of interprofessional education and collaborative practice as a core educational aim. ${ }^{4}$ Several groups have reported curriculum innovations around embedding students in interprofessional teams as a way to address this gap. ${ }^{5}$ Case Western Reserve University embedded students in an interprofessional care team to participate in the assessment and care of a defined panel of at-risk patients. City University of New York's first-year medical students participate in interprofessional shadowing experiences for exposure to team roles and return in subsequent years to follow patients through all aspects of their visits and to participate in value-added tasks such as medication reconciliation and development/dissemination of patient education tools. Robert Wood Johnson Medical School Interprofessional learner teams participate in home visits and in the development of a collaborative management plan that augments care for patients with complex needs. ${ }^{5}$

The purpose of this article was to describe the goals, development, implementation and feasibility of the first year of TEAM Clinic (Teach students, Empower patients, Act Collaboratively, Meet health goals) - an early clinical experience in which students participated in interprofessional collaborative care for patients with complex medical and social conditions as part of a longitudinal curriculum that teaches transformation of care. In this article, we describe the development and implementation of this curriculum innovation. Educational outcomes of the TEAM Clinic's experience will be reported later after several years of data collection and comparison of outcomes among nonparticipating students.

\section{Methods}

TEAM Clinic was developed by an interdisciplinary team of medical, pharmacy and behavioral health clinicians and educators. It was funded by a US Federal Department of Health and Human Services Health Resources and Services Administration Primary Care Training and Enhancement Project grant (HRSA-26-042, 07/2016-7/2021). Funding is for 5 years and will permit further curriculum improvements as well as methodology and evaluation beyond that reported in this article and over the course of our work. Approval was obtained from the University of Kentucky's institutional review board.

\section{Curriculum}

Core learning objectives for the TEAM Clinic's experience were identified by faculty in the University of Kentucky Colleges of Medicine (UKCOM), social work and pharmacy. Selection of specific learning objectives was based on the interprofessional competencies identified in the literature as being central to transformation of care. Disciplinespecific curriculum aims also guided this process. Two core Entrustable Professional Activities (EPAs) for entering residency as proposed by the American Association of Medical Colleges were selected: to collaborate as a member of an interprofessional team (EPA 9) and to identify system failures and contribute to a culture of safety and improvement (EPA 13). ${ }^{6}$ Social work faculty identified development of the following skills as key aims for the Masters of Social Work students participating in TEAM Clinic as part of an integrated behavioral health pathway: 1) identify determinants of health affecting patients with complex medical and social conditions and 2) collaborate with the team to develop an assessment and management plan that addresses social determinants of health. The pharmacy residency learning objectives were selected from those set forth by the American Society of Health-System Pharmacists (ASHP). These were as follows: to interact effectively with health care teams to collaboratively manage ambulatory care patients' medication therapy (R1.1.1); to interact effectively with ambulatory care patients, family members and caregivers (R1.1.2); analyze and assess information to ensure safe and effective medication therapy for ambulatory care patients (R1.1.4); demonstrate personal, interpersonal and teamwork skills critical for effective leadership (R3.1.1; Table 1). ${ }^{7}$

The TEAM Clinic curriculum was developed to address the abovementioned objectives through an augmented clinical experience. The structure was a half-day session that included facilitated discussion, robust interprofessional pre-visit planning, continuity clinical care of complex patients and 
facilitated reflection on patient care and team function. Core content included social determinants of health, care of complex patients and patient centeredness; the predominant instructional strategies employed were guided discussion, team participation, supervised patient interactions and facilitated reflection. Teamwork and team leadership were modeled and discussed as a cross-cutting theme throughout the program (Table 2).

\section{Logistics}

The clinical component of this experience took place at the University of Kentucky Family Medical Center. Resources utilized included clinical space (two rooms) and a precepting area. A licensed professional nurse (LPN) was assigned part-time to the clinic. Forty-minute visits were scheduled to incorporate multiple learners and an expanded scope of services. Considerations for a lowvolume clinic included revenue and faculty productivity bonus implications. Four to five patients were planned for this half day clinic. This volume of visits represents onehalf of typical volume; thus, $5 \%$ of the lead clinician time was covered as a cost to the grant.

\section{Patient recruitment}

The attending physician identified a subset of her continuity patients with multiple chronic medical and behavioral health conditions and social factors that negatively impact

Table I Learning outcomes for individual professions mapped to TEAM Clinic's learning activities

\begin{tabular}{|c|c|c|c|c|}
\hline $\begin{array}{l}\text { Learning outcomes for individual } \\
\text { professions }\end{array}$ & $\begin{array}{l}\text { Group } \\
\text { pre-visit } \\
\text { planning }\end{array}$ & $\begin{array}{l}\text { Supervised } \\
\text { IPE patient } \\
\text { assessment }\end{array}$ & $\begin{array}{l}\text { Clinical team } \\
\text { collaborative plan } \\
\text { development } \\
\end{array}$ & $\begin{array}{l}\text { Facilitated } \\
\text { reflection }\end{array}$ \\
\hline \multicolumn{5}{|l|}{ Medical students } \\
\hline $\begin{array}{l}\text { Collaborate as a member of an interprofessional } \\
\text { team (EPA 9) }\end{array}$ & $\cdot$ & $\cdot$ & $\bullet$ & \\
\hline $\begin{array}{l}\text { Identify system failures and contribute to a } \\
\text { culture of safety and improvement (EPA I3) }\end{array}$ & $\cdot$ & $\cdot$ & & $\cdot$ \\
\hline \multicolumn{5}{|l|}{ Masters of social work students } \\
\hline $\begin{array}{l}\text { Identify determinants of health affecting patients } \\
\text { with complex medical and social conditions }\end{array}$ & $\cdot$ & $\cdot$ & $\cdot$ & \\
\hline $\begin{array}{l}\text { Collaborate with the team to develop an } \\
\text { assessment and management plan that addresses } \\
\text { social determinants of health }\end{array}$ & $\cdot$ & $\cdot$ & $\cdot$ & \\
\hline \multicolumn{5}{|l|}{ Clinical pharmacist } \\
\hline $\begin{array}{l}\text { Interact effectively with health care teams } \\
\text { to collaboratively manage ambulatory care } \\
\text { patients' medication therapy (RI.I.I) }\end{array}$ & $\cdot$ & & $\cdot$ & \\
\hline $\begin{array}{l}\text { Interact effectively with ambulatory care } \\
\text { patients, family members and caregivers (RI.I.2) }\end{array}$ & & $\bullet^{a}$ & & \\
\hline $\begin{array}{l}\text { Analyze and assess information to ensure safe } \\
\text { and effective medication therapy for ambulatory } \\
\text { care patients (RI.I.4) }\end{array}$ & $\cdot$ & $\cdot$ & $\cdot$ & \\
\hline $\begin{array}{l}\text { Demonstrate personal, interpersonal and } \\
\text { teamwork skills critical for effective leadership } \\
\text { (R3.I.I) }\end{array}$ & $\cdot$ & $\cdot$ & $\cdot$ & \\
\hline
\end{tabular}

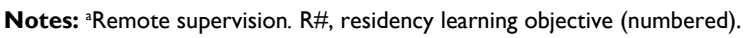

Abbreviations: EPAs, Entrustable Professional Activities; IPE, interprofessional experience; TEAM, Teach students, Empower patients, Act collaboratively, Meet health goals.

Table 2 TEAM Clinic's orientation topics and learning objectives

\begin{tabular}{|l|l|}
\hline Topics & Learning objectives \\
\hline Transformation of care & - Describe the purpose of the transformation of care curriculum \\
Complex patients & - Identify expectations for participation \\
Social determinants of health & - Define three characteristics of a "complex" patient \\
$\begin{array}{l}\text { Clinical pharmacist's role in the health care team } \\
\text { Clinical logistics and EHR }\end{array}$ & - Describe the scale of ACEs and how they may relate to complex patients \\
& - Reflect on provider reactions to complex patients \\
& - Recognize the impact of one or more social determinants of health on a patient \\
\hline
\end{tabular}

Abbreviations: ACEs, adverse childhood experiences; EHR, electronic health record; TEAM, Teach students, Empower patients, Act collaboratively, Meet health goals. 
health. Patients were tiered by the level of complexity through a subjective assessment by attending physician to systematically enroll patients in this clinic. The grant manager and LPN called and mailed letters to the first-tier (highest complexity) group explaining the purpose of the teaching clinic and inviting patients to participate in this study. Patients accepted verbally, and they were subsequently consented to participate at the time of clinic visits.

\section{Learner recruitment}

Medical student recruitment occurred prior to and after matriculation. A description of TEAM Clinic and link to its website were advertised to accepted candidates through the college's e-mail newsletter. Students indicating interest were also asked to provide information about prior experience with teamwork and population health. A key factor for recruitment was that TEAM Clinic was approved to fulfill (and exceed) the clinical requirements for Introduction to Clinical Medicine (ICM), a core curriculum course. ICM course directors offered this as an option for students when forming the ICM groups, thereby protecting student availability to participate in TEAM Clinic. An online application was open for 2 weeks, beginning the first week of classes. The application form inquired about prior experience and future practice plans in primary care, public health, health advocacy, health policy, leadership/ administration and clinical care. This was complemented by a brief statement regarding experience and motivation for interprofessional teamwork and marginalized populations. All applicants were accepted, and the program was expanded to accept an additional student for a total of nine medical students.

MSW students accepted to the integrated behavioral health pathway at the Family Medical Center were interviewed for two positions in the TEAM Clinic. They were selected based on having prior case management experience to advance their participation at the start of clinical activities.

A new ambulatory pharmacy residency program was in development during the planning period and presented an opportunity for additional interprofessional involvement. The advantage of this advanced-level trainee over a pharmacy student was additional knowledge, skills and the ability to practice independently with remote supervision, reducing the number of instructors who needed to be physically present in the clinical space.

\section{Implementation}

TEAM Clinic's participants were divided into two groups who participated in eight half-day sessions each over the course of the year. An orientation session introduced the overall goal of TEAM Clinic, reviewed specific learning objectives and established electronic health record (EHR) access. A critical item to address was the key issue of identifying and resolving scheduling conflicts to reduce losses of students finding themselves unable to attend due to other conflicts. All students provided written informed consent to participate.

The first two sessions of TEAM Clinic were dedicated to team formation and development of workflow by beginning with a discussion of the plan for the day and identifying roles. Subsequent sessions, over the first 3 months, began with narrative description of the patient by the attending physician, followed by interprofessional pre-visit planning discussions, wherein each team member shared their profession-specific approach to assessment. For example, the pharmacy resident reported on medication review and made recommendations for management or dose adjustment based on disease-specific or patient-specific factors. MSW students presented social determinants identified from the pre-visit chart review and discussed available resources to address the identified needs. Finally, the group made tentative plans for workflow during the session. This format provided both a model of true team-based interprofessional collaboration and a forum to provoke student questions and discussion concerning clinical pharmacology and therapeutics, mental health, social determinants of health and clinical practice of social workers and pharmacists. These discussions also prepared the team for collaborative plan formation at the conclusion of the patient visits. The sessions began with a discussion of concepts relevant to complex patient care and team-based care, including a model of health beliefs, impact of adverse childhood events and collaborative care in interprofessional teamwork. After discussion, the team engaged in a more compressed review of that day's patients and plan for the visit.

\section{Clinical workflow and learning activities}

As planned, four patients were scheduled per session with 40-minute appointment times for each (first two overlapping to provide less student downtime), allowing for teaching time and for real-time collaboration among interprofessional team members. Learning activities included taking vital signs with the LPN, administering mood disorder screenings with the MSW student, leading portions of the medication history and counseling with the pharmacy resident and engaging patients in preventive care discussions with physician supervision. Students also observed and participated in collaborative management discussions. In the latter portion of the year, medical students paired up to take a more comprehensive history, worked with the MSW students on assessments of social 
determinants and actively participated in the comprehensive medication review (CMR) with the pharmacy resident.

Facilitated reflection and debriefing were conducted with students as they finished their clinical interactions with the patients. The timing and number of students involved in any given discussion were necessarily flexible, but all students participated at least in some part of the debriefing each session. The debriefing activity was based on four open-ended questions to stimulate discussion and reflection: 1) What do you consider to be your patient's main barrier to better health outcomes? 2) How does this barrier impact your patient? 3) Where you able to communicate with the patient about the barrier/issue? If so, what did you discuss? 4) What was a high point of your clinic today? Debriefing sessions lasted approximately $30-45$ minutes. Later in the academic year, the students began to formulate their own questions and topics for the debriefing, often based on the patient they interacted with during that day's session.

\section{Outcome measures}

We used two instruments to characterize implementation of this curriculum. The first was the Authentic Clinical Interprofessional Experience (ACIPE) - Student Evaluation of Clinical Placement for Interprofessional Experience (IPE) tool which was created by the UK Center for Interprofessional Health Education in 2016 (unpublished questions are summarized in Table 3). In addition, we used the Saskatchewan Health Quality Council, Primary Health Care Survey - Long Version (2014) which, from a limited number of questions, provides a comprehensive scope of the patient experience. ${ }^{8}$ Study staff administered this survey electronically to each patient upon the completion of each visit. Participation was optional and anonymous. Medical students, MSW students and the pharmacy resident also pro-

Table 3 Overview of TEAM Clinic

\begin{tabular}{|l|l|}
\hline Pre-visit & Clinical interaction \\
\hline Lunch and learn & Interprofessional clinical care \\
- Social determinants & - Student health professional \\
- Health care gaps & dyads \\
Interprofessional & - Social determinant assessment \\
pre-visit planning & - Medication review \\
- Patient's story & - Collaborative assessment and \\
- Medication review & planning \\
& Facilitated reflection \\
& - Patient-specific determinants \\
\hline
\end{tabular}

Abbreviations: ACE, adverse childhood experience; TEAM, Teach students, Empower patients, Act collaboratively, Meet health goals. vided feedback through unstructured discussions throughout the experience.

\section{Results}

TEAM Clinic was developed and implemented as described with moderate revisions in the original design. Twelve learners including nine medical students, two MSW students and one pharmacy resident completed this clinical experience over 16 sessions. All learners and patients consented to participate in the study.

Program feedback was obtained using the ACIPE - Student Evaluation of Clinical Placement for IPE tool described earlier, informal student debriefings and an unstructured session with the pharmacy resident. Eleven of the total 12 learners completed the ACIPE survey. A 5-point Likert scale was used, and all 11 questions were answered as "agree" or "strongly agree" in support of TEAM Clinic as an effective ACIPE practice site (Table 4).

Additional unstructured postexperience feedback highlighted several opportunities. The pre-visit sessions were primarily led by the attending physician and could have included more participation of social work faculty for additional perspectives and different approaches to the assessment and care of complex patients. Likewise, more involvement of the pharmacy resident in the planning discussions could have aided to demonstrate the full scope and value of an ambulatory clinical pharmacist. For example, the primary role of the pharmacy resident was largely limited to consultation and collaborative planning but could have included more independent work such as direct patient education, CMR, independent medication therapy management and collaborative drug therapy management through collaborative practice agreements. Unstructured medical student feedback highlighted the impact of the practical and real-time education that occurred in discussion with the pharmacy resident. In addition, the medical students placed high value on having an introduction to interprofessional teams, becoming more confident and experienced with their patient interview skills and developed an appreciation for strategies to care for medically and socially complex patients.

Information about patient experience was collected using the Saskatchewan Health Quality Council, Primary Health Care Survey - Long Version (2014). ${ }^{8}$ All responses were positive across all questions with a response rate of $87 \%(\mathrm{~N}=46)$. Due to the structure of the TEAM Clinic and the patients in the sample, some patients provided multiple responses to these results as they had multiple visits to the TEAM Clinic. Patients gave the highest ratings regarding the following statements about 
Table 4 ACIPE - Evaluation of Interprofessional Clinical Practice Site (5-point Likert)

\begin{tabular}{|c|c|c|}
\hline Student evaluation of the preceptor & Mean & SD \\
\hline The instruction provided by the preceptor strengthened my knowledge and/or skills in providing care as part of a team & 1.36 & 0.51 \\
\hline The instruction provided by the preceptor strengthened my knowledge and/or skills in patient diversity and cultural sensitivity & 1.55 & 0.52 \\
\hline The instruction provided by the preceptor strengthened my knowledge and/or skills in professionalism and team cooperation & 1.45 & 0.52 \\
\hline The preceptor provided periodic feedback on my performance as part of the team & 1.27 & 0.47 \\
\hline Student evaluation of the site & Mean & SD \\
\hline The professionals contributed to an interprofessional and collaborative atmosphere & 1.27 & 0.47 \\
\hline The settings (inpatient, outpatient, pre-op, etc.) fostered an interprofessional and collaborative atmosphere & 1.36 & 0.51 \\
\hline There were adequate opportunities for me to learn and practice interprofessional skills & 1.55 & 0.52 \\
\hline Student evaluation of the interprofessional clinical team & Mean & SD \\
\hline Individual roles in the team were clearly identified & 1.45 & 0.52 \\
\hline I had a trusting relationship with my team members & 1.64 & 0.52 \\
\hline The team acknowledged comments and/or suggestions from each other & 1.64 & 0.52 \\
\hline The team was respectful to each other & 1.36 & 0.52 \\
\hline The team members cooperated successfully to provide patient care & 1.36 & 0.52 \\
\hline
\end{tabular}

Abbreviation: ACIPE, Authentic Clinical Interprofessional Experience.

the TEAM Clinic's experience: “[T]he best clinic/program possible" (10/10), "Overall, I had a very good experience" (10/10), "[D]id your doctor/care provider explain things in a way that was easy to understand?" (Yes, definitely), “[D]o you feel that your doctor/care provider listened and respected you as a partner in care?" (Yes, definitely), and "[D]id your doctor/care provider involve you in decisions about your care as much as you wanted?" (Yes, definitely). Patients indicated that wait time was "excellent" $(5 / 5)$. When asked "[h]ow informed and up-to-date was your doctor/care provider about the care you received from other care providers?" they indicated "very informed and up-to-date". In short, the patients found the TEAM Clinic's experience to be beneficial and did not perceive the average of 122 minutes from registration to discharge as too long (Table 5).

\section{Discussion}

TEAM Clinic was implemented and received positive learner ratings as an interprofessional clinical experience as well as positive patient ratings on the care experience. In addition, unstructured learner feedback highlighted important areas in which TEAM Clinic met student learning goals in addition to the program's learning objectives. Our project demonstrates the feasibility of implementing transformed clinical teaching experience by embedding students in a high-functioning clinical team to bridge a not-yet-transformed practice.

Describing considerations, resources and logistics of implementing a program with dual purpose - teaching and patient care - addresses the call for medical student's activities to provide value-added learning experiences that align with patient care goals. Importantly, devising solutions to the barriers of time, resources and infrastructure highlights
Table 5 Patient health satisfaction survey responses: selected questions related to team-based and patient-centered care

\begin{tabular}{|l|l|l|l|}
\hline Survey question & $\begin{array}{l}\text { Mean } \\
\text { score }\end{array}$ & Scale & Percent \\
\hline Clinical program & 9.39 & $0-10$ & 94 \\
\hline Overall experience & 8.50 & $0-10$ & 85 \\
\hline Understood explanation & 2.97 & $\mathrm{I}-3$ & 99 \\
\hline Felt respected/heard & 3.00 & $\mathrm{I}-3$ & 100 \\
\hline MD involved patient in decisions & 2.97 & $\mathrm{I}-3$ & 99 \\
\hline Wait time & 4.26 & $\mathrm{I}-5$ & 85 \\
\hline $\begin{array}{l}\text { MD/provider informed about } \\
\text { your care }\end{array}$ & 3.97 & $\mathrm{I}-4$ & 99 \\
\hline
\end{tabular}

Abbreviation: MD, medical doctor.

the need for logistical coordination of otherwise separate health professions education programs to promote interprofessional education and collaborative practice among trainees by recognizing alignment of educational goals and deliberate scheduling. Physical space constraints were an impediment to workflow to a moderate degree and should be considered in selecting clinical spaces and design. Cost of teaching time will continue to be an issue and needs to be addressed in future investigations. We can conclude that it is operationally feasible that early career medical students, social work students and pharmacy residents participate in interprofessional clinical teams as a means to teach IPE; and that this framework was an acceptable clinical model for our patients to receive care from interprofessional student teams.

\section{Limitations}

We identified several limitations in the design, implementation and measurement of this work. Revisions of the 
medical school curriculum structure and content prompted adaptation of the original design. We did not incorporate any specific measurement for knowledge and skill outcomes of curriculum due to the primary goal of establishing feasibility of implementation. This limits our ability to strongly state that changes in behavior were necessarily related to this curriculum as compared with students' core curricula. Student feedback collected was positive; however, this does not necessarily reflect that learning occurred. Our future research will implement measures of knowledge and skill acquisition. Patient satisfaction was high; however, this panel of patients could have a high baseline satisfaction with their ongoing care at the clinic. Therefore, we have no baseline for comparison to say that TEAM Clinic was satisfactory to them more so than usual care.

\section{Conclusion}

We have described the design and implementation of a curriculum innovation for teaching transformation of care through an early ACIPE. We conclude that it is feasible and beneficial for early career medical and social work students and pharmacy residents to participate in interprofessional clinical teams as a means to teach IPE; and that this framework is an acceptable clinical model for patients receiving care from interprofessional teams. Accordingly, this work advances information about how to implement clinical teaching that incorporates important elements of transformed care. In reports to come later, we will describe results of attitudinal surveys toward family medicine for a series of cohorts through years 1-4 of medical school.

\section{Acknowledgment}

TEAM Clinic was developed as part of a US Federal Department of Health and Human Services Health Resources Administration-funded Primary Care Training and Enhancement Project (Health Resources and Services Administra- tion-26-042, 07/2016-7/2021; William Elder, PhD, principal investigator).

\section{Disclosure}

Dr Melanie Dicks reports grants from US Federal HRSA Grant during the conduct of the study. Dr Keisa Fallin-Bennett reports grants from HRSA (US Health Resources Services Administration) during the conduct of the study. Dr William Elder reports grants from US DHS HRSA during the conduct of the study. The other authors report no conflicts of interest in this work.

\section{References}

1. Nyquist JG. Educating physicians: a call for reform of medical school and residency. J Chiropr Educ. 2011;25(2):193-195.

2. Lucey CR. Medical education: part of the problem and part of the solution. JAMA Intern Med. 2013;173(17):1639-1643.

3. Agency for Healthcare Research and Quality [homepage on the Internet]. Aligning Medical Education with the Nation's Health Priorities: Innovations in Physician Training in Behavioral and Social Sciences. Updated. 2015. http://www.ahrq.gov/professionals/education/curriculum-tools/ population-health/satterfield.html. Accessed June 16, 2018.

4. Long KA. The Institute of medicine report: health professions education: a bridge to quality. Policy, Politics, Nursing Practice. 2003;4(4):259-262.

5. American Medical Association. Creating a Community of Innovation. [portable document on the internet]. Chicago, IL: American Medical Association. [updated 2017]. Available from: https://www.ama-assn. org/sites/default/files/media-browser/public/about-ama/ace-monographinteractive_0.pdf. Accessed October 18, 2018.

6. Association of American Medical Colleges. Core Entrustable Professional Activities for Entering Residency: Curriculum Developers' Guide. [portable document on the internet. updated 2014]. Available from: https://members.aamc.org/eweb/upload/Core\%20EPA $\% 20$ Curriculum\%20Dev\%20Guide.pdf. Accessed October 18, 2018.

7. American Society of Health-System Pharmacists [homepage on the Internet]. Required competency areas, goals, and objectives for postgraduate year two (PGY2) ambulatory care pharmacy residencies. Copyright $^{\circ}$ 2017, American Society of Health-System Pharmacists, Inc. Available from: https://www.ashp.org/-/media/assets/professionaldevelopment/residencies/docs/pgy2-ambulatory-care-residencycompetency-areas-goals-objectives.ashx. Accessed October 18, 2018.

8. Saskatchewan Health Quality Council. Primary Health Care Patient Experience Survey 2014. [portable document on the internet. updated August, 2014]. Available from: https://hqc.sk.ca/Portals/0/documents/ patient-experience-survey-toolkit.pdf. Accessed October 18, 2018. reviewed, open access journal that aims to present and publish research on Medical Education covering medical, dental, nursing and allied health care professional education. The journal covers undergraduate education, postgraduate training and continuing medical education

\section{Dovepress}

including emerging trends and innovative models linking education, research, and health care services. The manuscript management system is completely online and includes a very quick and fair peer-review system. Visit http://www.dovepress.com/testimonials.php to read real quotes from published authors. 